Research Article

\title{
Projection of abnormal cold surge in winter over the northern part of Viet Nam using RegCM model according to RCP4.5 and RCP8.5 scenarios for 2020-2100 period
}

\author{
Hoa Vo Van ${ }^{1^{*}}$ \\ ${ }^{1}$ Northern Delta Regional Hydro-Meteorological Center; vovanhoa80@yahoo.com \\ *Correspondence: vovanhoa80@yahoo.com; Tel.: +84-912509932 \\ Received: 08 April 2021; Accepted: 25 June 2021; Published: 25 August 2021
}

\begin{abstract}
This article presents the results of projection of abnormal cold surge in winter in the Northern region of Vietnam for the period 2020-2100 based on the regional climate model RegCM under different scenarios Climate change RCP4.5 and RCP8.5 are generated from five Atmospheric-Ocean Global Circulation Models (AOGCM) including CNRM-CM5, CSIRO, MPI-ESM, EC-Earth and GFDL-ESM. The magnitude and variability of abnormal cold surge vary considerably across scenarios and across different global inputs. The estimated results show a decreasing trend of abnormal cold surge in winter over the Northern region in the period 2020-2100 under both scenarios RCP4.5 and RCP8.5. The reduction under the RCP8.5 scenario is larger than that of the RCP4.5 scenario. The frequency of abnormal cold surge in the early $21^{\text {st }}$ century is higher than in the middle and late $21^{\text {st }}$ century.
\end{abstract}

Keywords: Abonormal cold surge; Winter; Northern region of Viet Nam; RegCM model; RCP scenarios.

\section{Introduction}

Due to the influence of climate change, the climate regime in most regions of Vietnam has changed significantly in recent years. The increasing occurrence of abnormal cold surge in winter in the Northern region is one of the typical examples for the above-mentioned change in climate. Specifically, cold surges tend to occur more often with stronger intensity and create many extreme weather events such as the air temperature in many places dropping below 0 degrees Celsius, snow occurring in some places where never occurred in the observed data series. The question is how under the impact of climate change, how often has the occurrence of abnormal cold surge in winter changed in recent years and how will it change in the future according to different climate change scenarios?.

According to the study [1], cold extreme events bring air masses from high latitudes into mid-latitudes and low-latitudes, causing many extreme weather phenomena and have negative impacts on socio-economic activities and people. There have been many studies on extreme cold phenomena in winter done around the world, especially for East Asia. In it, two concepts have been proposed including "cold day" and "cold surge". The concept of a cold day was proposed in the study [2] which is defined as the day with the maximum anomaly of daily minimum/average temperature. Meanwhile, the cold surge was proposed in the study [3] which is based on the degree of sudden temperature drop over several consecutive days. In general, the concept of a cold day is usually associated with the average temperature value while a cold surge is associated with the variation of temperature 
by day. Therefore, global warming may be correlated with the change in the number of cold days but not necessarily with the number of cold surges.

[2] showed that in the context of increasing global temperature, the warming trend in East Asia is very large. The average temperature tends to increase and the distribution function shifts towards the higher temperature range, leading to the low temperature extremes also increasing. This result leads to a decrease in the number of cold days as shown in the study [4]. The decrease in the number of cold days in East Asia was also shown in the studies. [8] showed that no clear trend was found in the variation of the number of cold extremes in Europe and the United States, although global temperatures are trending upward direction. To date, there have been many studies on the characteristics of extreme cold surge [9-10] and their relationship with large-scale circulation [9-11] in East Asia. However, there are very few studies on the trends of these phenomena as well as the effects of global warming on the trends of changes in these phenomena. extreme cold in the northern part of Viet Nam.

In this paper, we apply the RegCM regional climate model version 4.6.2 to estimate the change of abnormal cold surge over the Northern region in the period 2020-2100 based on the RCP4.5 and RCP8.5 scenarios are generated from 5 atmospheric-ocean global circulation models (AOGCM). Subsequent sections present detail the method for identifying abnormal cold surge, the data set used, and the expected results.

\section{Dataset and Methodology}

\subsection{Definition of abnormal cold surge và model data process}

The method to determine abnormal cold surge in winter in the Northern region is proposed based on the study [12]. If $\mathrm{T}_{10 \mathrm{pi}, \mathrm{j}, \mathrm{k}}$ is called the 10th percentile of the average daily temperature value of the jth day in the kth month at the ith station, a day is defined as occurering abnormal cold surge event if the average temperature of given day is smaller

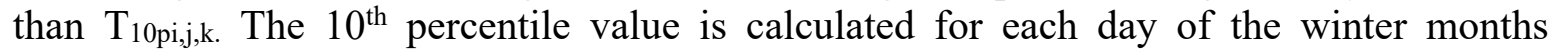
(November to March of the next year) based on the IPCC method which uses a dataset of 10-day time windows (where the given day in time window is 5 days).

For simulation and estimated data according to RCP scenarios from RegCM model (daily temperature data are provided on the model grid), theoretically it can be determined on grid space as in the study [13] or at the station point by interpolating values from the regional climate model grid. In order to minimize the effect of differences in the resolution of regional climate models used, the differences of the simulated and estimated datasets under the RCP scenarios, in this study we choose the method of determining the abnormal cold surge from the space-based RegCM climate model of 84 monitoring stations in the Northern region. With this option, the air temperature data simulated and estimated according to the RCP scenarios from the climate models will be interpolated to the station point. The interpolation method that will be used is the nearest point interpolation method. The temperature data after being interpolated will be corrected to limit the influence of errors. The bias correction method is used according to the study [14].

\subsection{Regional climate model configuration}

In order to enhance the ability to capture the weather patterns that govern the abnormal cold surge in winter in the northern region, the integral region of the RegCM model extends to the north. Specifically, the integral domain center is selected at $20^{\circ} \mathrm{N}$ and $110^{\circ} \mathrm{E}$ with the 138 grid points along to latitude and longitude direction corresponding to a resolution of 32 $\mathrm{km}$ in each direction. Figure 1 illustrates the integral domain for the RegCM model and the study area (northern part of Viet Nam). 

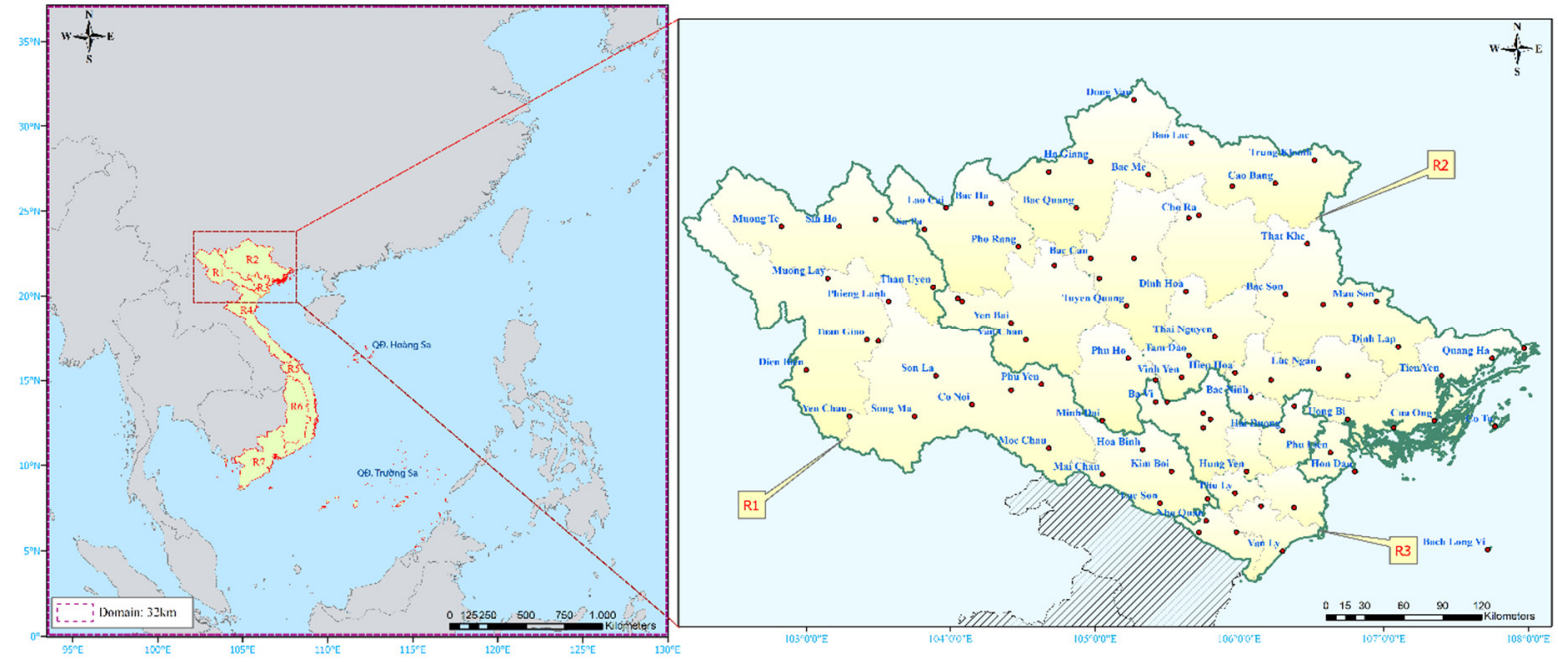

Figure 1. Integal domain of RegCM (left side) and distribution of 84 synoptic station in research region (right side).

Table 1 shows some configuration of the RegCM model. In fact, the RegCM model provides a wide selection of physical parameterization schemes for research purposes. However, the paper does not conduct experimental research and select suitable physical parameterization schemes for the current problem. Hence, the selection of physical parameterization schemes is based on local studies was made. Specifically, the selection of physical parameterization schemes for the RegCM model in this study is based on the research results of Phan Van Tan et al (2014) [14]. The physical configuration is fixed for both of RCP4.5 and RCP8.5 scenarios.

Table 1. The configuration of RegCM model.

\begin{tabular}{lc}
\hline \multicolumn{1}{c}{ Configuration } & RegCM (ver. 4.6.2) \\
\hline Grid center point & $20^{\circ} \mathrm{N} ; 110^{\circ} \mathrm{E}$ \\
Grid point & $138 \times 138$ \\
Horizontal resolution & $32 \mathrm{~km}$ \\
Vertical pressure levels & 18 \\
Cumulus parameterization scheme & Grell-AS \\
Soil parameterization scheme & BATS \\
Radiation parameterization scheme & CCM3 \\
\hline
\end{tabular}

\subsection{Global datasets}

In order to have input data (initial and boundary conditions) for the RegCM model, it is necessary to use the climate projection dataset of the global models. In this study, we use estimated data under RCP4.5 and RCP8.5 scenarios from 5 AOGCM that is generated in the Couple Model Intercomparison Project (CMIP). Information about these models is given in Table 2 below. These global datasets were collected from 1986 to 2100 in which period of 1986-2005 was used to calculated the baseline.

Table 2. General information of five AOGCM are used as input data for RegCM model.

\begin{tabular}{clll}
\hline $\begin{array}{c}\text { Model } \\
\text { name }\end{array}$ & \multicolumn{1}{c}{ Developer } & Resolution & \multicolumn{1}{c}{ Data link } \\
\hline CNRM- & $\begin{array}{l}\text { Centre national de } \\
\text { Recherches }\end{array}$ & $1.41 \times 1.40$ & $\mathrm{http} / / \mathrm{www} . u m r-\mathrm{cnrm} . \mathrm{fr} / \mathrm{cmip} 5 /$ \\
MPI- & $\begin{array}{l}\text { Max Planck Institute for } \\
\text { ESM }\end{array}$ & \multirow{2}{*}{$1.875 \times 1.85$} & $\begin{array}{l}\mathrm{https} / / \mathrm{www} . \mathrm{mpimet.mpg.de} / \mathrm{en} / \mathrm{science} \\
/ \mathrm{models} / \mathrm{mpi}-\mathrm{esm} /\end{array}$ \\
\hline
\end{tabular}




\begin{tabular}{clcl}
\hline $\begin{array}{c}\text { Model } \\
\text { name }\end{array}$ & \multicolumn{1}{c}{ Developer } & Resolution & \multicolumn{1}{c}{ Data link } \\
\hline $\begin{array}{c}\text { EC- } \\
\text { Earth }\end{array}$ & EC-Earth consortium, & $1.125 \times 1.125$ & http://www.ec-earth.org/ \\
CSIRO & CSIRO, Australia & $1.875 \times 1.86$ & $\begin{array}{l}\text { https://data.gov.au/dataset/ } \\
\mathrm{https} / / \mathrm{www} . g f d l . n o a a . g o v / \text { earth-system- } \\
\text { model/ }\end{array}$ \\
$\begin{array}{c}\text { GFDL- } \\
\text { ESM }\end{array}$ & GFDL, USA & $2.5 \times 2.0$ & \\
\hline
\end{tabular}

\section{Results and discussion}

Figure 2 to Figure 6 show the results of projecting the number of abnormal cold surge in winter in the Northern region according to the RCP4.5 and RCP8.5 scenarios for the period 2020-2100 from the RegCM model with input from 5 different global models. From these figures it can be seen that the number of cold surges projected for each winter during 2020-2100 is highly variable between other global inputs as well as between the two RCP scenarios. The frequency of cold spells in the early 21 st century is much higher than in the late 21 st century. In which, most of the estimated tests show a sudden increase in the number of abnormal cold surges during the period of 2030-2050 according to both scenarios. The sudden increase in period of 2080-2100 was found only when looking at the projected results from the EC-Earth and GFDL-ESM inputs. In comparison with the baseline period (1986-2005), the number of abnormal cold surge projected from the different global input tests and under the 2 scenarios is generally much higher during 2020 2065 and lower during the period of 2070-2100. Some estimates show that there are some years with very larger sudden increase (more than 25 abnormal cold surges in comparison with normal).

The difference between the number of abnormal cold surge occurring in the same year between scenarios and between different global inputs is on average about 3-4 events. There is some possibility that the deviation between the two scenarios is very large such as, for example, in 2022, the expected outcome with input from the global model CNRM-CM5 under the RCP4.5 scenario is only 2 abnormal cold surges, while under the RCP8.5 scenario is 22 abnormal cold surges.

During the first half of the 21 st century, the estimated outcome under the RCP4.5 scenario with input from the CNRM-CM5 and CSIRO gives a greater number of abnormal cold surge than in the RCP85 scenario. However, estimates with input from EC-Earth, MPI-ESM and GFDL-ESM models give the opposite result. For the second half of the $21 \mathrm{st}$ century, all projections from the global input year show a higher number of abnormal cold surge under the RCP4.5 scenario than under the RCP8.5 scenario, especially is in the last part of the decade (2080-2100).

The changing trend of the number of abnormal cold surge in the whole 2020-2100 period is little change or slight decrease under both scenarios. The results of statistical hypothesis testing show that most of the trends satisfy the statistical hypothesis with the $90 \%$ confidence level, but not at the 95 and 99\% confidence levels. A rapid downward trend is found in the period 2020-2040 and slight or little change in the remaining years.

Figure 7 shows the results of calculating the ensemble mean variation trend from 5 different global inputs for the RegCM model under the RCP4.5 and RCP8.5 scenarios for the period 2020-2100. A downward trend in abnormal cold surge can be seen in both scenarios in which the decrease in RCP8.5 scenario is faster than in RCP4.5 scenario. This result is completely logical because the RCP8.5 scenario is a high emission scenario that will give a rapid global warming trend, especially in the late $21^{\text {st }}$ century. On average, according to the RCP4.5 scenario, most winters in the period 2020-2100 are expected to have more abnormal cold surge than the baseline period with an average increase of 2-3 events per year. 


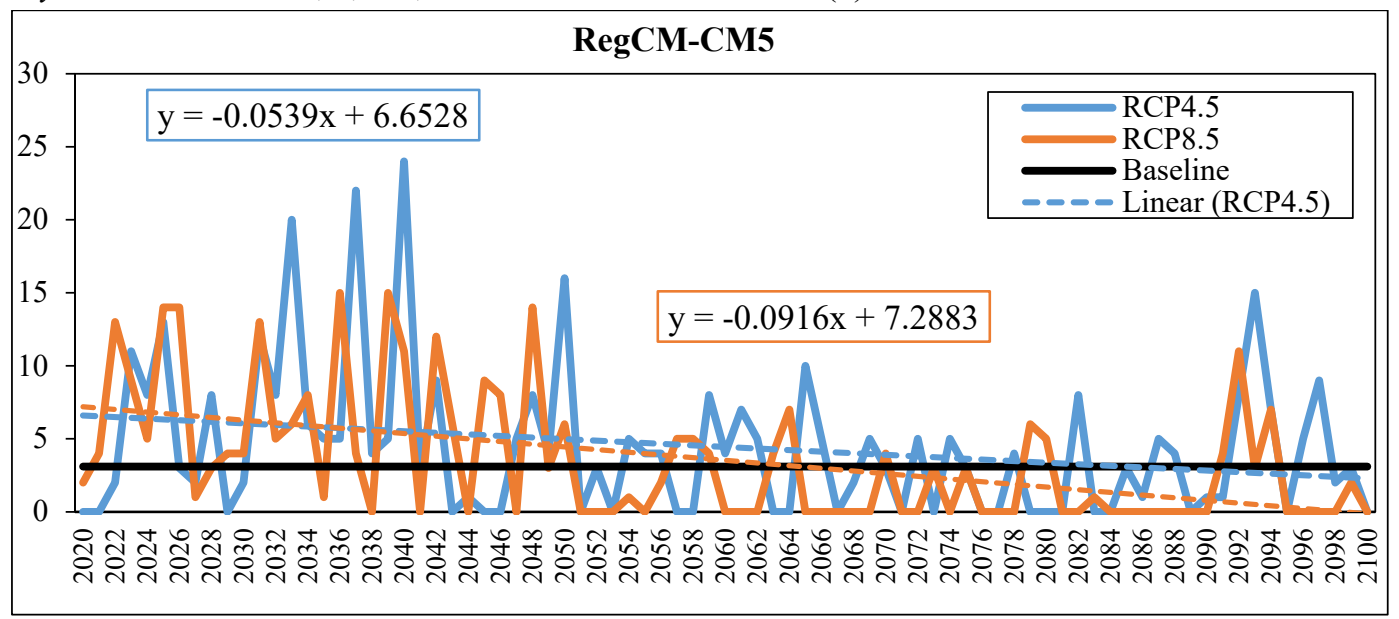

Figure 2. Projection of abnormal cold surge in winter over the northern part of Viet Nam using RegCM model according to RCP4.5 and RCP8.5 scenarios for 2020-2100 period with inputs of CNRM-CM5 global model.

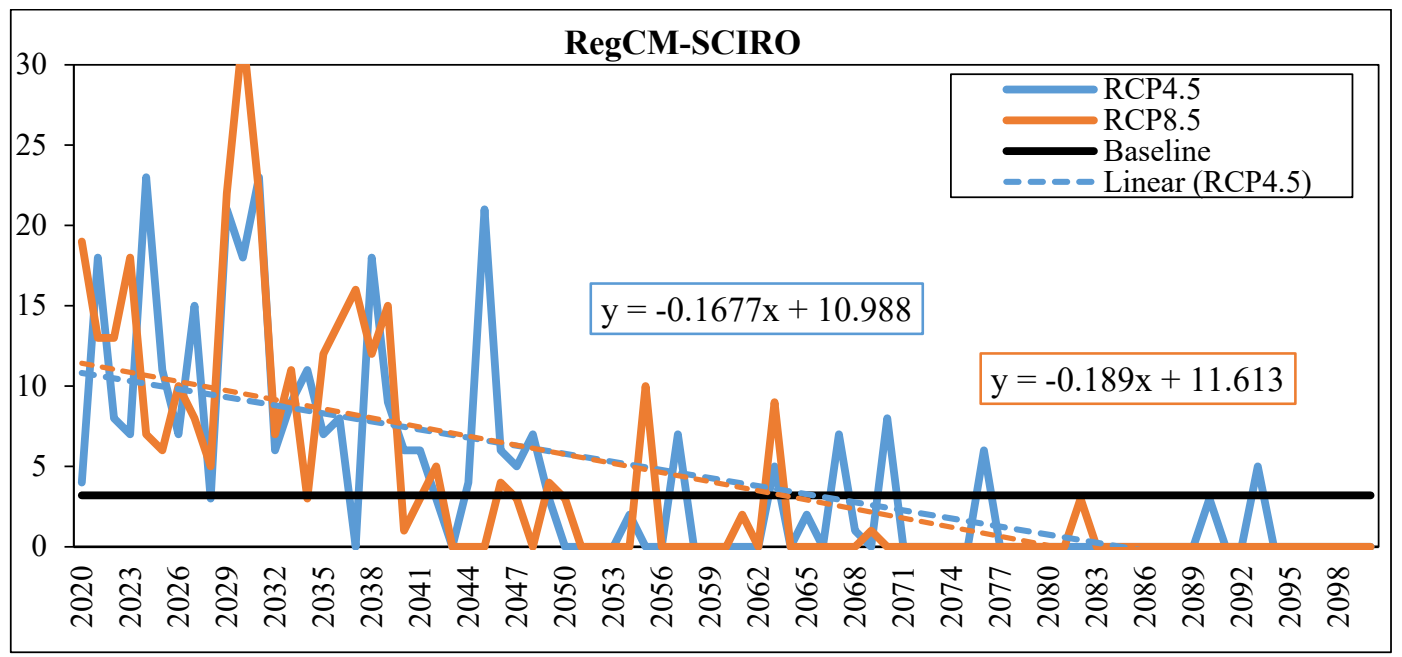

Figure 3. Projection of abnormal cold surge in winter over the northern part of Viet Nam using RegCM model according to RCP4.5 and RCP8.5 scenarios for 2020-2100 period with inputs of SCIRO global model.

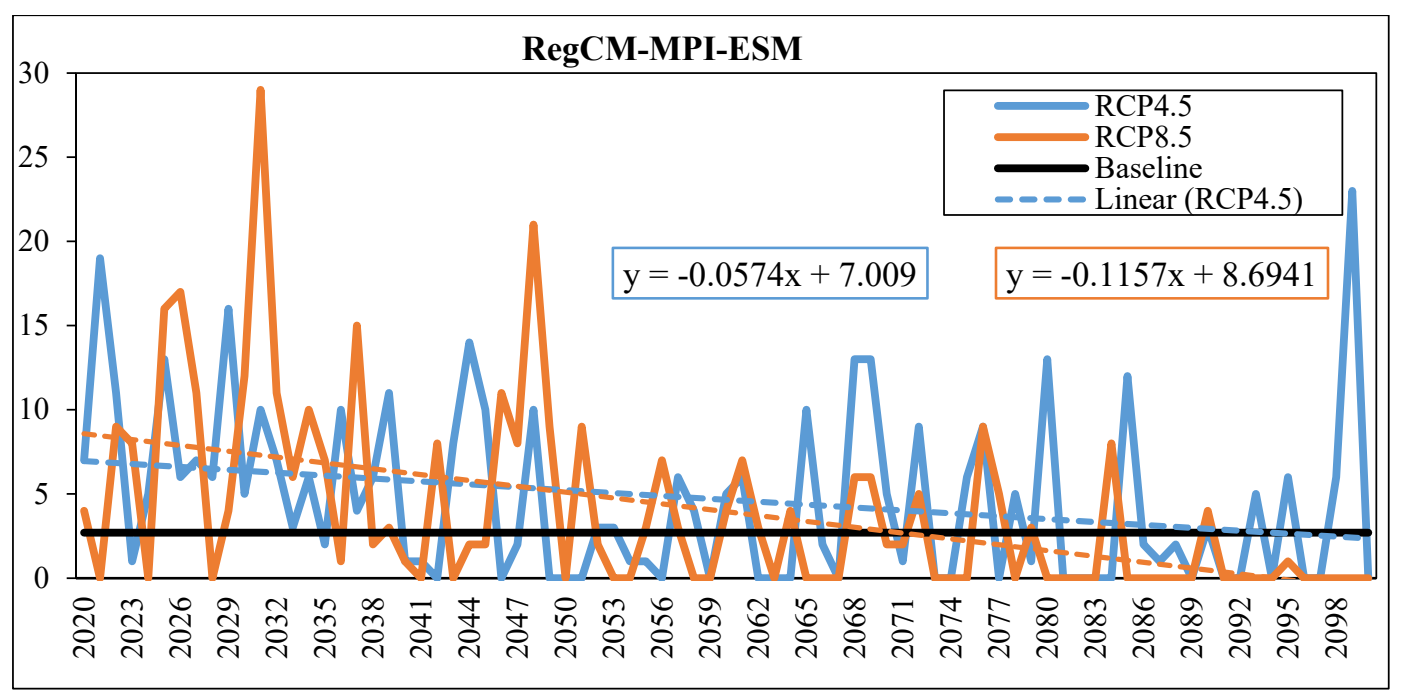

Figure 4. Projection of abnormal cold surge in winter over the northern part of Viet Nam using RegCM model according to RCP4.5 and RCP8.5 scenarios for 2020-2100 period with inputs of MPI-ESM global model. 


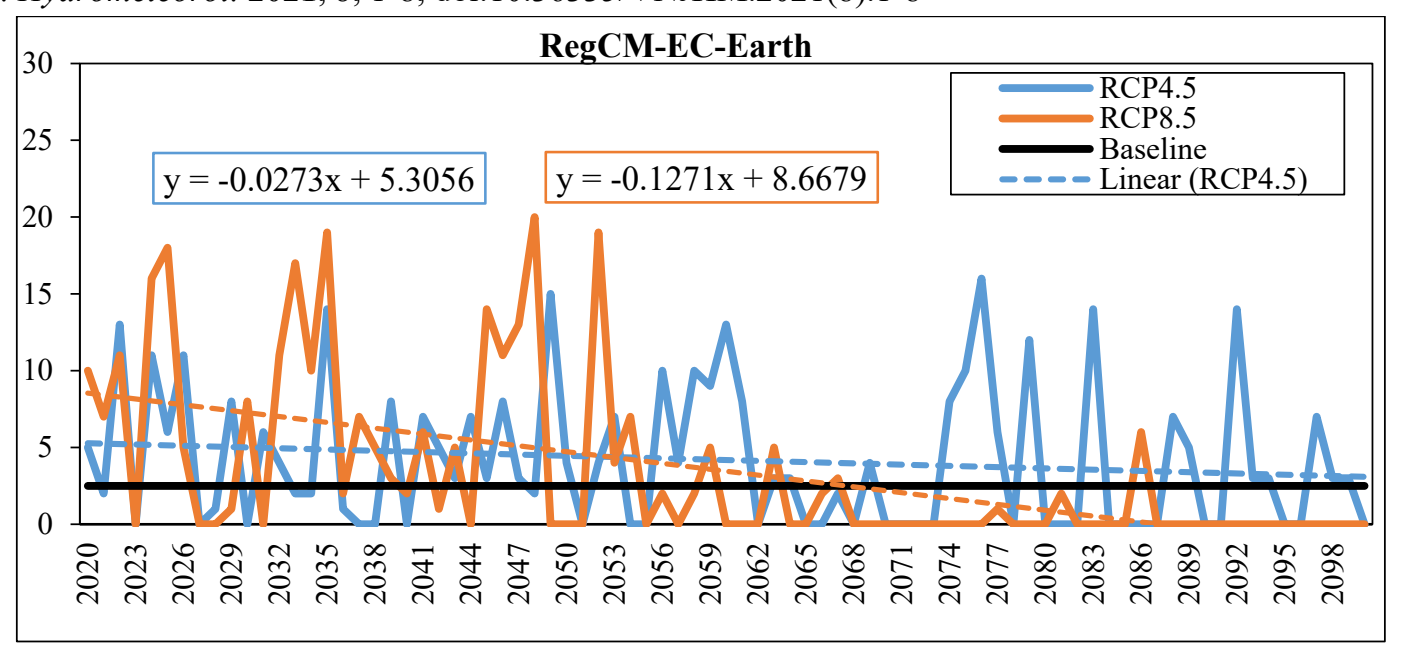

Figure 5. Projection of abnormal cold surge in winter over the northern part of Viet Nam using RegCM model according to RCP4.5 and RCP8.5 scenarios for 2020-2100 period with inputs of EC-Earth global model.

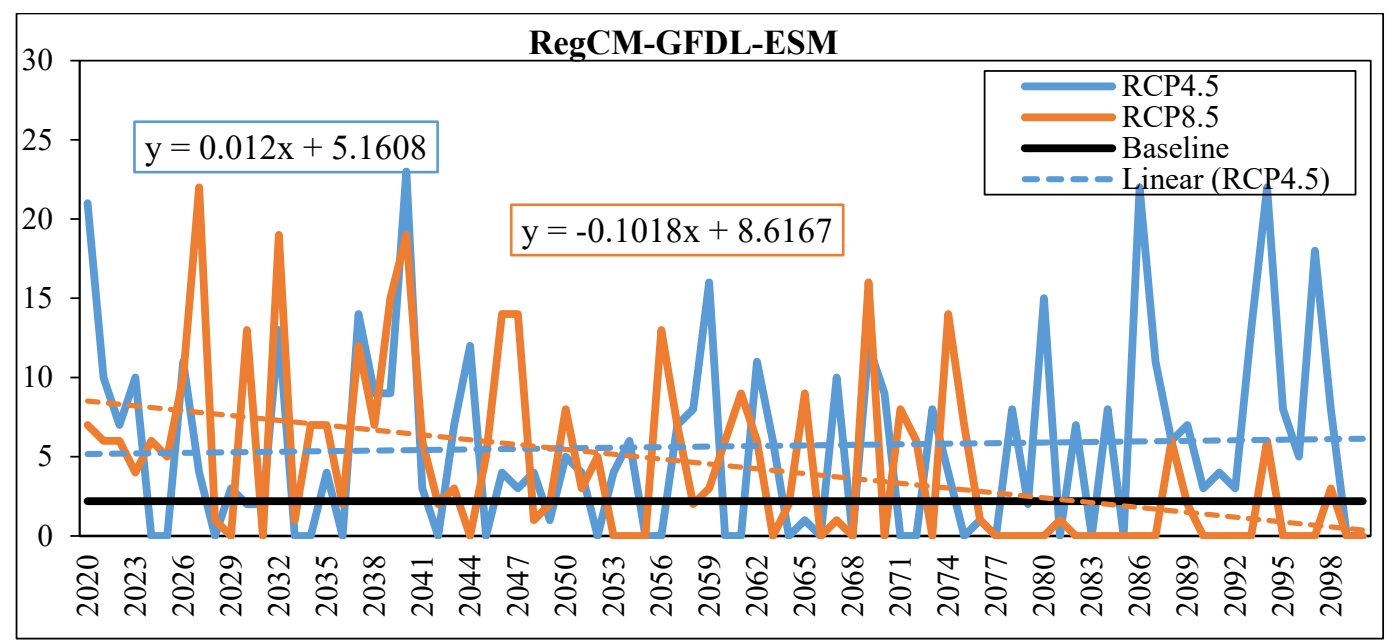

Figure 6. Projection of abnormal cold surge in winter over the northern part of Viet Nam using RegCM model according to RCP4.5 and RCP8.5 scenarios for 2020-2100 period with inputs of GFDL-ESM global model.

However, with the RCP8.5 scenario, the sudden increase compared to the baseline period is only found in the period 2020-2050. For the period 2050-2100, the number of abnormal cold surge decreased faster and less than the baseline period, especially in the late $21^{\text {st }}$ century. In order to take a closer look at the changing trends of abnormal cold surge in winter in the Northern region under the scenarios RCP4.5 and RCP8.5, we calculate the separate changing trends for the $21^{\text {st }}$ century (2045-2065) and the end of the $21^{\text {st }}$ century (2080-2100). Calculation results show that the general trend of abnormal cold surge in winter in the Northern region is decreasing or less changing. With the same global input, the number of abnormal cold surge projected for each year and under the two scenarios is also different with an average difference of 1-2 events. In general, compared with the early $21^{\text {st }}$ century, the number of abnormal cold surge projected under both scenarios is significantly reduced for The changing trend of the number of abnormal cold surge in the whole 2020-2100 period is little change or slight decrease under both scenarios. The results of statistical hypothesis testing show that most of the trends satisfy the statistical hypothesis with the $90 \%$ confidence level, but not at the 95 and $99 \%$ confidence levels. A rapid downward trend is found in the period 2020-2040 and slight or little change in the remaining years. 


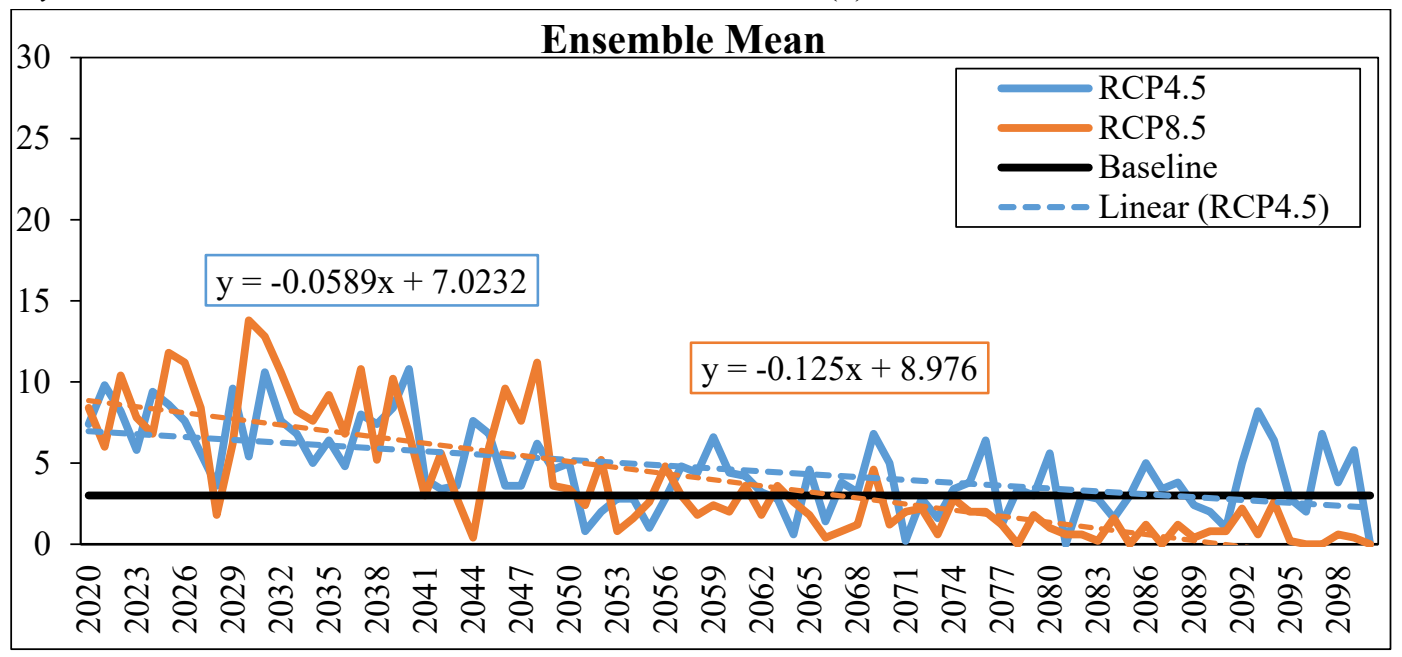

Figure 7. Projection of abnormal cold surge in winter over the northern part of Viet Nam using RegCM model according to RCP4.5 and RCP8.5 scenarios for 2020-2100 period with ensemble mean of five global model.

For the end of the $21^{\text {st }}$ century, the projected outcome is very different between different global inputs as well as between two scenarios with the same global input. Calculation results show that at this stage, abnormal cold surge in the Northern region are almost rare under the RCP8.5 scenarios as seen in the projected results with input from the CSIRO model. The total number of abnormal cold surge expected to occur during this period under the RCP4.5 scenario is much larger than that of the RCP8.5 scenario. Under the RCP8.5 scenario, there are only a few years during this period where there are more abnormal cold surge than the baseline period. Meanwhile, according to the RCP4.5 scenario, about $50-60 \%$ of winters in this period have more abnormal cold surge events than in the baseline period. In terms of trend, both scenarios show little change or slight uptrend. Especially in the last 10 years of the $21^{\text {st }}$ century, it can be seen that projections from global inputs show a slight increase trend. The results of the statistical hypothesis testing show that the trends found do not satisfy the statistical hypothesis with the $90 \%$ or more confidence level.

\section{Conclusion}

This article presents the results of projection of abnormal cold surge in winter in the Northern region of Vietnam for the period 2020-2100 based on the regional climate model RegCM under different RCP4.5 and RCP8.5 climate change scenarios are generated from five AOGCM including CNRM-CM5, CSIRO, MPI-ESM, EC-Earth and GFDL-ESM. The magnitude and trend of variation vary considerably between scenarios and between different global inputs. However, if considering the same scenario and AOGCM input, the estimated results from the RegCM model is only quantitatively different (number of occurrences), while in terms of trends it is almost the same. The estimated results show a decreasing trend of abnormal cold surge in winter in the Northern region in the period 2020-2100 under both scenarios RCP4.5 and RCP8.5. The reduction under the RCP8.5 scenario is larger than that of the RCP4.5 scenario. The frequency of abnormal cold surge in the early 21 st century is higher than in the middle and late $21^{\text {st }}$ century.

Author Contributions: Conceived and designed the experiments: T.T.L.; Analyzed and interpreted the data: T.T.L.; contributed reagents, materials, analysis tools or data: T.T.L., N.M.L.; manuscript editing: V.V.H.; Performed the experiments: T.T.L.; contributed reagents, materials, analyzed and interpreted the data, wrote the draft manuscript: T.T.L., V.V.H., N.M.L. 
Acknowledgements This work was supported by the Ministry of Natural Resources and Environment through the national Project "The impact of climate change on abnormal cold surge and heat wave in the winter at the Viet Nam northern mountain areas to serve for socio-economic development" (code: BDKH.25/16-20).

Conflicts of Interest: The authors declare no conflict of interest.

\section{References}

1. Kunkel K.E.; Pritke, R.A.; S.A. Changnon. Temporal fluctuation in weather and climate extremes that cause economic and human health impacts - a review. Bull. Amer. Meteor. Soc. 1999, 80, 1077.

2. Trenberth, K.E. Observations: Surface and atmospheric climate change, in Climate Change 2007: The Physical Science Basis. Cambridge Univ. Press, Cambridge, U.K. 2007, 235-336.

3. Boyle, J.S.; Chen, T.J. Synoptic aspects of the wintertime East Asian monsoon, in Monsoon Meteorology. Oxford Univ. Press, Oxford, U.K. 1987, 125-160.

4. Alexander, L.V.; Zhang, X.; Peterson, T.C.; Caesar, J.; Gleason, B.; Klein Tank, A. M.G.; Haylock, M.; Collins, D.; Trewin, B.; Rahimzadeh, F.; Tagipour, A.; Rupa Kumar, K.; Revadekar, J.; Griffiths, G.; Vincent, L.; Stephenson, D.B.; Burn, J.; Aguilar, E.; Brunet, M.; Taylor, M.; New, M.; Zhai, P.; Rusticucci, M.; Vazquez-Aguirre, J.L. Global observed changes in daily climate extremes of temperature and precipitation. 111(D5). doi:10.1029/2005jd006290 J. Geophys. Res. 2006, 111(D05109), pp.22. https://doi.org/10.1029/2005JD006290.

5. Zhai, P.; Pan, X. Trends in temperature extremes during 1951-1999 in China. Geophys. Res. Lett. 2003, 30(17), 1913. https://doi.org/10.1029/2003GL018004.

6. Gong, D.Y.; Ho, C.H. Intra-seasonal variability of wintertime temperature over East Asia. Theor. Appl. Climatol. 2004, 24, 131-144.

7. Choi, Y.S.; Ho, C.H.; Gong, D.Y.; Jeong, J.H.; Park, T.W. Adaptive change in intra?winter distribution of relatively cold events to East Asian warming. Terr. Atmos. Oceanic Sci. 2009, 20, 807-816.

8. Walsh, J.E.; Phillips, A.S.; Portis, D.H.; Chapman, W.L. Extreme cold outbreaks in the United States and Europe, 1948-99. J. Clim. 2001, 14, 2642-2658. https://doi.org/10.1175/1520-0442(2001)014<2642: ECOITU>2.0.CO;2.

9. Takaya, K.; Nakamura, H. Mechanisms of intraseasonal amplification of the cold Siberian high. J. Atmos. Sci. 2005, 62, 4423-4440. https://doi.org/10.1175/JAS3629.1.

10. Jeong, J.H.; Kim, B.M.; Ho, C.H.; Chen, D.; Lim, G.H. Stratospheric origin of cold surge occurrence in East Asia, Geophys. Res. Lett. 2006, 33, L14710. https://doi.org/10.1029/2006GL026607.

11. Jeong, J.H.; Ho, C.H. Changes in occurrence of cold surges over East Asia in associated with Arctic Oscillation. Geophys. Res. Lett. 2005, 32, L14704. https://doi.org/10.1029/2005GL023024.

12. Shabbar, A.; Bonsal, B. An assessment of changes in winter cold and warm spells over Canada. Nat. Hazards 2003, 29(2), 173-188.

13. Park, T.W.; Ho, C.H.; Jeong, S.J.; Jeong, Y.S.; Choi, S.K.; Park, S.K.; Song, C.K. Different characteristics of cold day and cold surge frequency over East Asia in a global warming situation. J. Geophys. Res. 2011, 116, D12118. https://doi.org/10.1029/2010JD015369.

14. Tân, P.V. Nghiên cứu xây dựng hệ thống mô hình dự báo hạn mùa cho một số hiện tượng khí hậu cực đoan phục vụ phòng tránh thiên tai ở Việt Nam. Báo cáo tổng kết đề tài KHCN cấp Nhà nước, mã số ĐT.NCCB-HUD.2011-G/09, 2014, 350 . 